\title{
Formar e pesquisar para quê?
}

Érika Dias a, b

Neste primeiro número de 2018, a revista Ensaio: Avaliação e Políticas Públicas em Educação apresenta aos seus leitores uma gama de artigos que discutem temas e objetos do campo educacional que são de grande importância para a nossa e para outras realidades.

As pesquisas aqui publicadas buscam expor um conjunto de saberes que visam à disseminação de conhecimentos variados - como formação de professores, gestão democrática do ensino público, educação especial, Prova Brasil, formação de pesquisadores, Tecnologias da Informação e da Comunicação (TICs), educação do campo, práticas educacionais abertas e neurociências -, temas cada vez mais complexos e mais pesquisados. Essa multiplicidade de abordagens reforça a pluralidade da Ensaio, linha pela qual a revista tem se pautado e se destacado na área da Educação. Esse destaque foi confirmado com a atribuição de conceito A1 da Capes no último quadriênio (2013-2016), reconhecendo o esforço da equipe editorial e a qualidade dos artigos que publicamos, que visam, sobretudo, colaborar com o debate na área da Educação.

Contudo, vale frisar que este número acabou por convergir com um tópico recorrente nos periódicos da área: a formação. Trata-se de tema transversal nos campos de investigação que tem contribuído para o amadurecimento de pesquisadores iniciantes e também para aqueles já consagrados por seus trabalhos e legados. E uma das maiores questões sobre esse assunto é: em tempos de crise, formar para quê?

Para oferecer respostas e caminhos a esta indagação, a Ensaio apresenta neste número artigos que tratam de diversos tipos de formação, como de professores e de pesquisadores, além da ampliação do currículo para melhorar o trabalho docente. Também são abordadas as formações específicas para os professores que vão ensinar no campo ou que precisam aprender práticas inclusivas para trabalhar com crianças com necessidades educativas especiais. Sendo assim, o assunto tornou-se o fio condutor que une o conjunto de artigos que constituem este número.

\footnotetext{
a Fundação Cesgranrio - Rio de Janeiro, RJ, Brasil.

b Universidade Nova de Lisboa - UNL, Lisboa, Portugal.
} 
E esta não foi uma escolha aleatória. Os textos se alinham à nossa missão de divulgar pesquisas científicas que visem ampliar o debate e a disseminação de ideias na área educacional, assim como "espelham angústias da nossa época e do nosso espaço" (GOMES, 2017, p. 282).

O conjunto de artigos aqui apresentados está em sintonia com a busca de uma melhor formação acadêmica que permita ao professor melhorar em sala de aula, seja no âmbito da Educação Básica seja no âmbito da Educação Superior, ou mesmo em subáreas tão distintas quanto a da Tecnologia da Informação e da Comunicação e a da Educação Especial. Afinal, conforme Paulo Freire (2002), formação, educação e ensino sempre estiveram lado a lado com a pesquisa:

Não há ensino sem pesquisa e pesquisa sem ensino. Esses fazeres se encontram um no corpo do outro. Enquanto ensino continuo buscando, reprocurando. Ensino porque busco, porque indaguei, porque indago e me indago. Pesquiso para constatar, constatando, intervenho, intervindo educo e me educo. Pesquiso para conhecer o que ainda não conheço e comunicar ou anunciar a novidade (p. 14).

Iniciamos esta edição do periódico com um texto de pesquisadores da região Nordeste que analisam as condições político-institucionais relativas à gestão democrática do ensino público nos sistemas municipais de educação do estado do Piauí. Os autores, Raimunda Ribeiro e Elton Nardi, no artigo intitulado "Bases normativas e condições político-institucionais da gestão democrática em sistemas municipais de ensino do estado do Piauí" discutiram a gestão democrática, a participação e a autonomia no conjunto das bases normativas dos recentes sistemas municipais de ensino daquele Estado, indicando o esforço por configurações convergentes com o princípio da gestão democrática do ensino público. Os autores compreenderam que um dos pontos em causa era o avanço das condições para que o cidadão participasse direta e ativamente das decisões políticas e de gestão da educação pública, a partir do conceito de democracia participativa.

Da região Centro-Oeste, temos o artigo de Bruno Teles Nunes, intitulado "Teacher education: is it beating its head on a brick wall?", que tratou especificamente da formação dos professores que atuam na Educação Básica. Bruno Nunes utilizou os dados do Sistema Universidade Aberta do Brasil, para os anos de 2006 a 2015, e demonstrou como a maioria das vagas foram direcionadas à formação de professores, tanto para formação inicial quanto para a complementar. Com base nos números discutidos no seu texto, o autor concluiu que o Sistema UAB alcançou seu objetivo como política pública indutora da formação de professores. Contudo, inferiu que 
problemas ligados à carreira docente acabam por desestimular os alunos a ingressarem e finalizarem os seus cursos. Seu artigo aponta caminhos para a resolução deste problema.

O terceiro artigo se insere no campo da Educação Superior e trata da formação de professor para atuar nos Institutos Federais. Os autores, Ailton Paulo de Oliveira Júnior, Martha Maria Prata-Linhares e Acir Mário Karwoski, da região Sudeste, verificaram, no artigo intitulado "Formação docente no contexto brasileiro das instituições federais de Educação Superior", o atual contexto de ampliação e consciência do papel de responsabilidade no trabalho docente por parte do professor, bem como examinaram a tendência crescente de que a formação continuada seja mais uma nova forma de regulação profissional. Os resultados da pesquisa apontam para algumas ações nos institutos federais que podem melhorar a formação docente, tais como a institucionalização de programas de formação com a criação de setores e coordenadorias e a valorização de programas de monitoria e de tutoria, ampliando a compreensão da docência para muito além do simples domínio das técnicas de ensino.

O quarto artigo trata do entendimento dos professores lusos no que respeita à inclusão. Oriundo de Portugal, o texto dos pesquisadores Paulo César Azevedo Dias e Irene Maria Dias Cadime, debate a realidade diferente da nossa - de um país com cerca de 10 milhões de habitantes e com um sistema educativo dividido em ciclos. Os autores recorreram a uma amostra de 118 educadores de infância portuguesa, a quem administraram um "inventário de inclusão" a fim de compreender de que forma as práticas inclusivas são percebidas pelos educadores. Os pesquisadores destacam que parece existir um campo fértil para o desenvolvimento e avaliação de ações de formação contínua com o propósito de promover conhecimentos sobre as necessidades educativas especiais.

Estes artigos demonstram que para haver uma boa prática docente, uma boa participação popular e um bom entendimento do que são práticas educativas inclusivas é preciso existir uma boa formação. Tal premissa já foi apontada por Dermeval Saviani (2011):

[...] O entendimento de que o trabalho docente é condicionado pela formação resulta uma evidência lógica, assumindo o caráter consensual do enunciado de que uma boa formação se constitui em premissa necessária para o desenvolvimento de um trabalho docente qualitativamente satisfatório. Inversamente, é também consensual que uma formação precária tende a repercutir negativamente na qualidade do trabalho docente (p. 17). 
Da região Sudeste, temos também o artigo intitulado "A 'realidade' de cada escola e a recepção de políticas educacionais", dos autores Rodrigo Rosistolato, Ana Pires do Prado e Leane Rodrigues Martins. Em seu texto, os pesquisadores analisaram a Prova Brasil, procurando entender porque determinados setores criticavam a implementação desta política pública - uma avaliação em larga escala -, quando eram favoráveis à avaliação de uma forma geral. Os autores perceberam que o principal argumento contrário às avaliações em larga escala é o suposto desrespeito às "realidades escolares" e entenderam que gestores de uma determinada Secretaria Municipal de Educação, gestores de escolas e representantes sindicais não conseguiam compreender que as avaliações em larga escala não pretendiam substituir as avaliações internas e que não classificavam as escolas com base em critérios únicos. Segundo os pesquisadores, era esta falta de entendimento que levava às críticas à política pública.

Adriano de Oliveira e Lucídio Bianchetti, do Sul, no artigo intitulado "Iniciação Científica Júnior: desafios à materialização de um círculo virtuoso", fruto de pesquisa financiada pelo $\mathrm{CNPq}$, abordaram a trajetória da institucionalização da iniciação científica e da iniciação científica júnior no país, tendo como pano de fundo a Universidade Federal de Santa Catarina, demonstrando como esta política pública é relevante.

Do Chile temos o artigo intitulado "Percepción de los profesores sobre integración de TIC en las prácticas de enseñanza en relación a los marcos normativos para la profesión docente en Chile", dos autores Marcelo Arancibia Herrera, Daniela Cosimo Fernández e Roberto Casanova Seguel, que em sua pesquisa buscaram relacionar as percepções dos professores sobre o uso da tecnologia e sua ligação com uma política pública denominada "Normas e competências TIC para a Profissão Docente".

Marilene Santos, da Universidade Federal de Sergipe, no artigo "Educação do Campo no Plano Nacional de Educação: tensões entre a garantia e a negação do direito à educação", analisou o direito à educação para as populações do campo e demonstrou a garantia desse direito nos documentos que fundamentam a política educacional no Brasil nas últimas décadas.

André Chiappe, da Colômbia, e Silvia Irene Adame, do México, no artigo "Open Educational Practices: a learning way beyond free access knowledge", analisaram as práticas educacionais abertas, demonstrando como estas têm se tornado uma crescente tendência educacional, baseada em Tecnologia de Informação e Comunicação. Os autores acreditam que transformar conteúdos educacionais e somente disponibilizá-los não é suficiente para produzir inovação educativa. Para eles, a inovação exige que as práticas educacionais se tornem de fato abertas. 
Para fechar a revista, na seção Página Aberta trazemos um artigo singular que também versa sobre formação e educação, mas com um enfoque que incide em áreas aparentemente díspares: economia e neurociências. $\mathrm{O}$ artigo de Diego de Carvalho e Cyrus Antônio Vilas Boas, intitulado "Neurociências e formação de professores: reflexos na educação e economia", discute as relações entre educação, macroeconomia e formação de professores. Os autores afirmam que, se os educadores estudassem neurociências durante a sua formação, poderiam utilizar esse conhecimento para adequar seus métodos de ensino, aumentando sua eficiência e preparando melhor novos profissionais para o mercado.

Formação, educação, pesquisa e ensino - esta é a gama de assuntos que esta edição traz à tona para discutir com os leitores. Respondendo à nossa pergunta inicial, entendemos que, sem uma formação adequada, não há qualidade e acreditamos que, para haver qualidade e uma boa formação, as condições de trabalho também precisam ser levadas em conta. Sem pesquisa não há conhecimento e o conhecimento traz o desenvolvimento econômico e social. Assim, formação, educação, pesquisa e ensino se complementam e se completam.

Estamos cientes de que o número 98 é publicado em um momento de grandes mudanças políticas e econômicas no Brasil, as quais impactam na esfera educacional do país, seja pelas transformações empreendidas pelo Ministério da Educação (MEC) seja pela falta de recursos anunciada pelo governo Federal, que até gerou uma emenda constitucional, por serem estes tempos de recessão.

Possivelmente neste ano - de Eleições e de Copa do Mundo - será implementada de forma efetiva a Base Nacional Comum Curricular (BNCC) que regulará toda a Educação Básica do país, trazendo alterações singulares em todos os currículos. Sabemos que a produção de políticas é um processo complexo composto por diferentes forças, contendo em seu âmago o desafio de dar voz aos diferentes sujeitos (DIAS; PONCE, 2015). Discutir toda esta pluralidade é papel do governo e da sociedade. A nosso ver, se todos levarem em conta que alterações significativas só serão conseguidas quando a Educação for eixo de um projeto de desenvolvimento nacional, a BNCC, enquanto parte deste projeto, poderá de fato ser uma mudança bem-sucedida, se houver um comprometimento do governo e da sociedade em prol de uma Educação que beneficie a todos.

Mas sobre este tema e sobre estas e outras mudanças muito ainda será escrito e nós, certamente, teremos o que debater com os nossos leitores. 


\section{Referências}

DIAS, R. E.; PONCE, B. J. Formação docente frente às políticas no cenário de centralização curricular. E-Curriculum, São Paulo, v. 13, n. 4, p. 612-615, 2015. Disponível em: $<$ https://revistas.pucsp.br/index.php/curriculum/article/ view/26154/18791>. Acesso em: 14 dez. 2017.

FREIRE, P. Pedagogia da autonomia: saberes necessários à prática educativa. 25. ed. São Paulo: Paz e Terra, 2002.

GOMES, C. A. C. EditoriaL. Ensaio: Avaliação e Políticas Públicas em Educação, Rio de Janeiro, v. 25, n. 95, p. 277-282, 2017. doi: http://dx.doi.org/10.1590/s0104-40362017002500001.

SAVIANI, D. Formação de professores no Brasil: dilemas e perspectivas. Poíesis Pedagógica, v. 9, n. 1, 2011, p. 7-19. doi: https://doi.org/10.5216/rpp.v9i1.15667

\section{Informações da autora}

Érika Dias: Editora Adjunta da revista Ensaio: avaliação e políticas públicas em Educação da Fundação Cesgranrio. Doutora pela Universidade Nova de Lisboa (UNL), Lisboa, Portugal; investigadora correspondente do Centro de História de Humanidades da UNL. Contato: erikadias@cesgranrio.org.br 